\title{
The Effect of Ca and Mg Concentrations and Quantity and Their Correlation with Caries Intensity in School-Age Children
}

\author{
Milaim Sejdini, ${ }^{1}$ Kastriot Meqa $\mathbb{D}^{2},{ }^{2}$ Nora Berisha $\left(\mathbb{D},{ }^{1}\right.$ Ekrem Çitaku, ${ }^{3}$ Nora Aliu, ${ }^{1}$ \\ Sokol Krasniqi, ${ }^{1}$ and Sami Salihu ${ }^{4}$ \\ ${ }^{1}$ Department of Orthodontics, Faculty of Medicine, University of Prishtina, Prishtina, Kosovo \\ ${ }^{2}$ Department of Periodontology and Oral Medicine, Faculty of Medicine, University of Prishtina, Prishtina, Kosovo \\ ${ }^{3}$ Department of Orthodontics, University Dentistry Clinical Center of Kosovo, Prishtina, Kosovo \\ ${ }^{4}$ Department of Maxillofacial Surgery, Faculty of Medicine, University of Prishtina, Prishtina, Kosovo
}

Correspondence should be addressed to Kastriot Meqa; kastriot.meqa@uni-pr.edu

Received 26 February 2018; Accepted 2 April 2018; Published 8 May 2018

Academic Editor: Francesco Inchingolo

Copyright (c) 2018 Milaim Sejdini et al. This is an open access article distributed under the Creative Commons Attribution License, which permits unrestricted use, distribution, and reproduction in any medium, provided the original work is properly cited.

Introduction. Saliva is a watery product formed by the salivary glands and secreted in the mouth. Besides the fundamental factors, saliva with its ingredient is one of the main etiologic factors of caries presence. In the development of dental caries, the relationship between demineralization and remineralization is influenced by the presence of saliva, which facilitates the transportation of ions, oral bacteria, and fermentable carbohydrates to the exposed surfaces of teeth. The main components of saliva electrolytes are sodium, calcium, copper, magnesium, bicarbonates, and organic phosphates. Increase in calcium level in the remineralization solution may enhance the deposition velocity of minerals in the caries lesion. Magnesium, except the similar role as calcium, takes an active part in cellular reparation process. Materials and Methods. In this study were included students of age 12-13. Students were divided into three groups; the first group included caries-free children, the second group with DMF $=1-6$, and the third group with DMF $>6$. Fully stimulated and nonstimulated saliva was collected in sterile graded patches in the morning hours, due to the circadian rhythm in 5-minute length. Chemical analyzes have been conducted at the Faculty of Chemistry, Ss. Cyril and Methodius University in Skopje. Statistical processing has been performed at the Medical Faculty, at the Institute of Medical Statistics in Skopje. Results. Depending on the DMF, before and after stimulation, regarding Ca level, no significant differences were found. However, the Ca level prior to stimulation is significantly higher in the second group compared to the third one. Also, the amount of Ca after stimulation in the first group was significantly higher. No significant differences in $\mathrm{Mg}$ level and amount were found prior to and after stimulation, while the amount of Mg after stimulation had a significant difference between groups. Conclusion. Saliva mineral analysis has shown significant differences in quantitative and qualitative components between examining groups. The decrease of calcium molality in saliva might play a significant role in caries occurrence; thus, we may suppose that saliva calcium level significantly influences hard dental tissues defense mechanism. Magnesium levels after stimulation showed a significant difference between groups I and III and no significant differences between groups I and II. Magnesium level and amount correlate with calcium level, favoring elemental caries resistance.

\section{Introduction}

Saliva is a watery substance formed in the mouth, secreted by the salivary glands. Human saliva contains $99.5 \%$ water, but also many important substances, including electrolytes, mucus, antibacterial compounds, and various enzymes. The joint action of factors in derived full saliva provides a multifunctional defense system, which might fail only if the salivary flow is greatly reduced [1].
Saliva contributes to the digestion of food and to the maintenance of oral hygiene. Without normal salivary function, the frequency of dental caries, gum disease, and other oral problems increases significantly. We still do not have reliable diagnostic procedures to predict such a particular risk in the pediatric and adolescent age. Although many questions remain unanswered, however, it is commonly acknowledged that saliva and the influence of its components are important for oral health. 
There are many different agents within saliva and plaque that serve to protect the tooth surface against caries development. Salivary flow rate, buffering capacity, antimicrobial activity, microorganism aggregation and clearance from the oral cavity, immune surveillance, and calcium phosphate binding proteins, all interact to inhibit or reverse demineralization of exposed tooth surfaces.

Saliva contains a supersaturated solution of calcium and phosphate, which neutralizes acids. Many factors might affect the quantity and quality of saliva. Secretion of saliva is under the control of the autonomous nervous system, which controls both the volume and type of saliva secreted. Mixed and unstimulated saliva derives from a general secretive system of oral cavity glands in the unstimulated environment, where no dietary substance influences taste or other receptors in the oral cavity. It is thought that caries varies on the following two inseparable variables: enamel and its surrounding environment. Most of the electrolytes are found in all types of salivary glands, although their level may differ within various glands. Secretion of saliva may be stimulated or triggered mechanically, dietarily, electrically, or pharmacologically; furthermore, it relies on cholinergic and betaadrenergic glandular stimulation. There is an obvious difference in salivary electrolyte levels, deriving from different sources. The parotid saliva contains more phosphate and less $\mathrm{Ca}^{+2}$ ions compared to mixed saliva. On the contrary, the level of $\mathrm{Ca}^{+2}, \mathrm{Mg}^{+2}$, and $\mathrm{Zn}^{+3}$ in mixed saliva is significantly higher, compared to the parotid one.

In terms of the relationship between dietary mineral intake and oral disease, the calcium $(\mathrm{Ca})$ and phosphorus $(\mathrm{P})$ concentrations of dental plaque and the levels of $\mathrm{Ca}$ and $\mathrm{P}$ ions in the saliva could affect the balance between demineralization and remineralization of enamel [2].

Some epidemiological studies have revealed that humans with relatively high $\mathrm{Ca}$ and $\mathrm{P}$ in their plaque experience correspondingly lower caries [3]. Higher Ca concentration of plaque is associated with low caries incidence [4].

Dental caries is a microbial disease of the calcified tissues of the teeth, characterized by demineralization of the inorganic portion and destruction of the organic substance of the tooth. There is no universally accepted opinion of the etiology of dental caries.

Demineralization and remineralization have a crucial impact on the hardness and strength of tooth enamel. The battle to keep teeth strong and healthy is dependent upon the ratio between demineralization and remineralization. Demineralization occurs at a low $\mathrm{pH}$ when the oral environment is undersaturated with mineral ions, relative to a tooth's mineral content. The enamel crystal, which consists of carbonated apatite, is dissolved by organic acids (lactic and acetic) that are produced by the cellular action of plaque bacteria in the presence of dietary carbohydrates. Loss of Ca ions (phosphorus and fluoride) of supersaturated saliva enables demineralizing tissue recovery. Increasing $\mathrm{Ca}$ concentration in the remineralizing solution can increase the rate of deposition of minerals in the lesion. Increasing $\mathrm{Ca}$ level within a remineralizing solvent may increase mineral incorporatinglayering velocity. In the development of dental caries, the relationship between demineralization and remineralization is influenced by the presence of saliva, which facilitates the transportation of ions, oral bacteria, and fermentable carbohydrates to the exposed surfaces of teeth. It is this complex interrelationship that we must understand better in order to fight the battle of maintaining tooth integrity.

Magnesium ( $\mathrm{Mg}$ ) may also play an important role in preventing periodontal disease and caries as it has the unique ability to reduce inflammation caused by bacterial toxins [5].

Similarly, $\mathrm{Mg}$ has also been shown to have both significant [6] and no significant associations with tooth decay [7].

\section{Aim}

The aim of this research is to determine $\mathrm{Ca}$ and $\mathrm{Mg}$ amount and concentration in unstimulated and stimulated saliva with children at high risk of caries with $\mathrm{DMF}>6$ and $\mathrm{DMF}=1-6$ and with the group of caries-free children, to determine if there is a correlation between the $\mathrm{Ca}$ and $\mathrm{Mg}$ amount and concentration compared to the caries frequency between the three investigated groups, to find the effect of $\mathrm{Ca}$ and $\mathrm{Mg}$ values in the saliva in preventing caries, and to determine the correlation between concentration and amount of $\mathrm{Ca}$ and $\mathrm{Mg}$ in unstimulated and stimulated saliva in the three investigated groups of children.

\section{Materials and Methods}

Student examination was performed in school settings, involving children of 12-13 years of age. The survey comprised 1248 students. Subjects were divided into three groups; first group listing caries-free ones $(\mathrm{DMF}=\mathrm{O})$, the second with DMF $=1-6$, and the third one listing those with $\mathrm{DMF}>6$. Out of the total number of subjects (106), the first group comprised 25 subjects, the second group 47, and the third one 34 . For examinee classification purposes, in the first group, the WHO method on intensity index of measured caries was utilized. Furthermore, oral hygiene maintenance awareness with children groups at this age is satisfactory. With all examinees, full-blended and nonstimulated saliva was studied. All examinees' saliva samples were collected in graded sterile tubes, in the morning hours from 8:00 to 9:00, before intake, at least an hour after brushing. Saliva was collected for 5 minutes, soaked with pipe injector out of mouth flour, and spilled into a sterile tube. Total saliva in strict time frames was collected. During examination time, the patients were calm, sitting, and not allowed to swallow. After a while, sterile paraffin to chew was given, for the same exact 5-minute period. Collection of stimulated saliva and other related procedures were conducted in an identical manner as with the nonstimulated one. All tubes collected (212) were cultured at $-20^{\circ} \mathrm{C}$, enabling bacteria and enzyme inactivation, thereof probably influencing the biochemical and immunochemical analysis.

Chemical and immunochemical tests have been conducted in the Faculty of Science, Ss. Cyril and Methodius University in Skopje. Analyses were performed by flame atomic absorption spectrometer model Solaar S4 from Thermo Elemental (UK); for Ca analysis, we used the wavelength of $422.7 \mathrm{~nm}$, spectral slit of $0.2 \mathrm{~nm}$, and lamp 


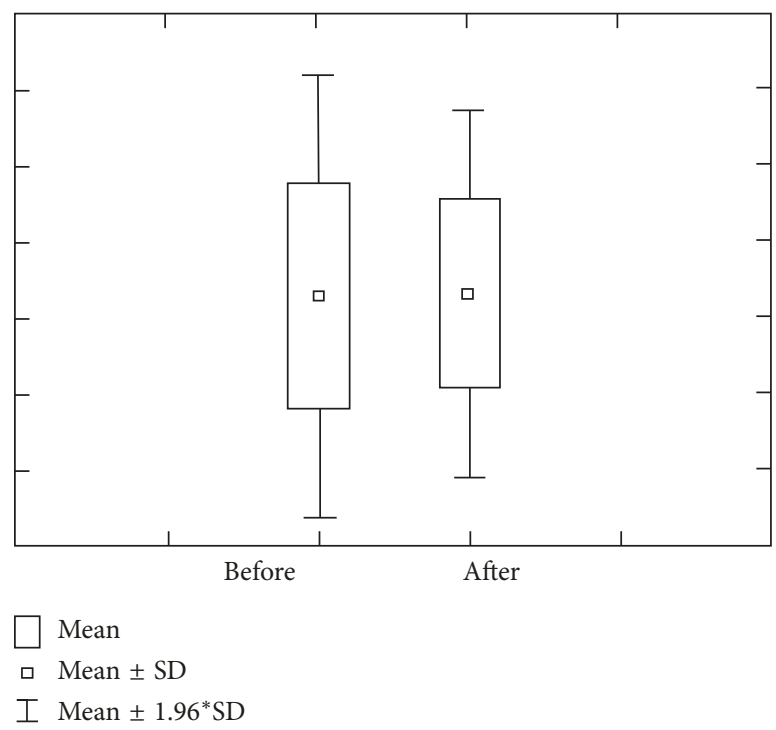

Figure 1: Concentration and quantity of Ca before stimulation for the first group of investigated subjects $(\mathrm{DMF}=0)$.

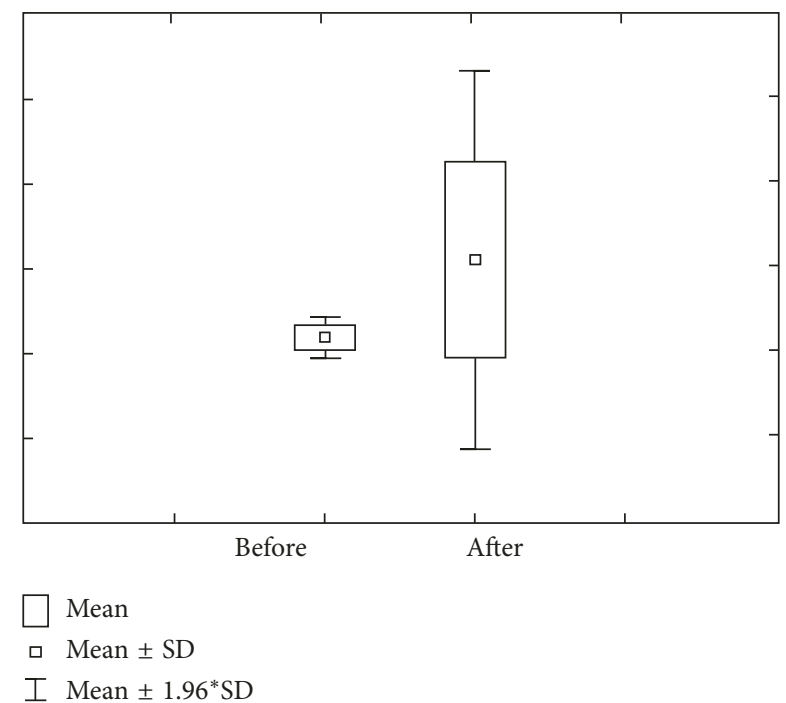

FIgURE 2: Concentration and quantity of $\mathrm{Ca}$ after stimulation for the first group of investigated subjects $(\mathrm{DMF}=0)$.

current of $10 \mathrm{~mA}$, while for $\mathrm{Mg}$ analysis, the wavelength of $285.2 \mathrm{~nm}$, spectral slit of $1.0 \mathrm{~nm}$, and lamp current of $4 \mathrm{~mA}$, which represents a method with relatively high sensitivity. For the analysis of $\mathrm{Ca}$ and $\mathrm{Mg}, 2 \mathrm{ml}$ of saliva samples were diluted with redistilled water in the volumetric flask of $25 \mathrm{ml}$ by adding few drops of concentrated nitric acid.

Data were statistically processed at the Institute of Medical Statistics, Faculty of Medicine in Skopje. Average values, standard deviations, confidence interval, Mann-Whitney $U$ test, Kruskal-Wallis $\mathrm{H}$ test, $t$-test, Wilcoxon matched pair (Z), analysis of variance $(\mathrm{F})$, and so on were determined.

\section{Results}

Figures 1 and 2 show concentration and amount of Ca before and after paraffin stimulation. The concentration of Ca prior

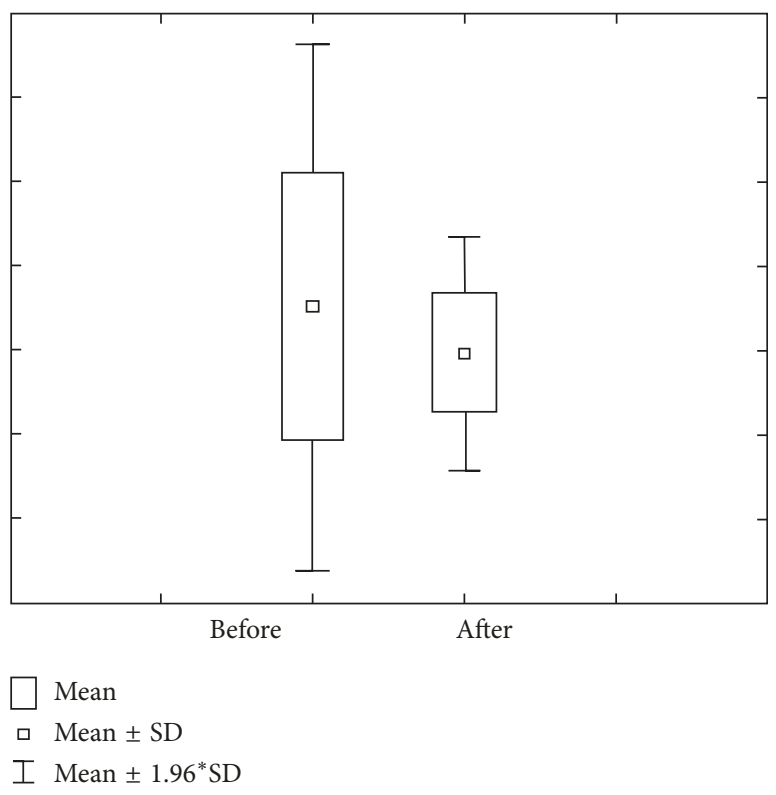

FIGURE 3: Concentration and quantity of $\mathrm{Mg}$ before stimulation for the first group of investigated subjects $(\mathrm{DMF}=0)$.

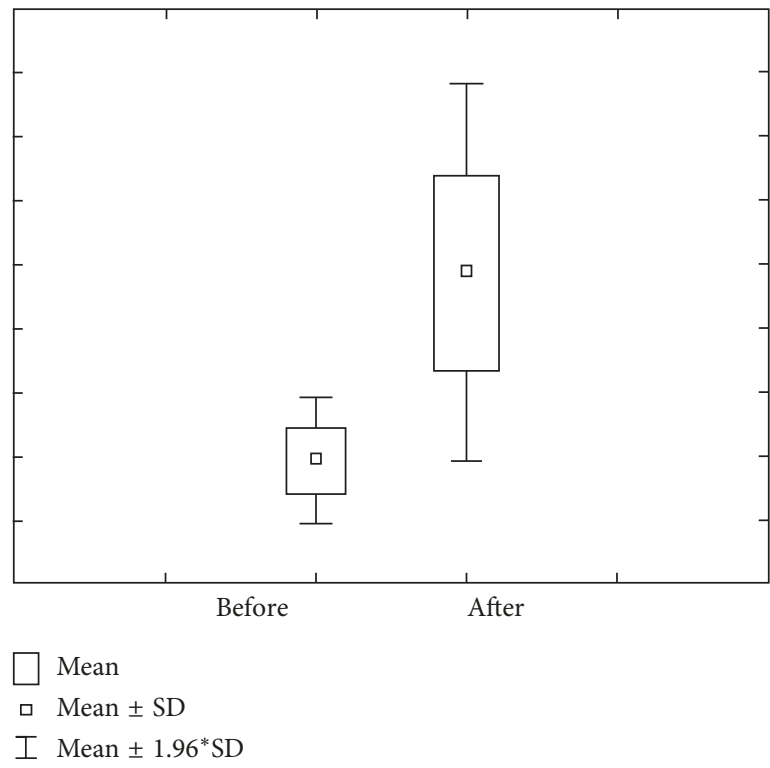

Figure 4: Concentration and quantity of $\mathrm{Mg}$ after stimulation for the first group of investigated subjects $(\mathrm{DMF}=0)$.

to stimulation in the first group varies within $1.29 \pm$ $1.48 \mathrm{mmol} / \mathrm{L}$ ranges, with $0.67-1.90$ confidence interval. The concentration of $\mathrm{Ca}$ after stimulation varies within $1.30 \pm$ $1.22 \mathrm{mmol} / \mathrm{L}$ ranges, with $0.80-1.81$ confidence interval. Ca amount prior to stimulation varies within $1.80 \pm 1.23 \mu \mathrm{mol} / \mathrm{L}$ ranges, with 1.29-2.31 confidence interval. Ca amount after stimulation varies within $10.91 \pm 11.47 \mu \mathrm{mol} / \mathrm{L}$ ranges, with 6.17-5.65 confidence interval.

Figures 3 and 4 show concentration and quantity of $\mathrm{Mg}$ before and after stimulation. We can notice that concentration of $\mathrm{Mg}$ before the stimulation level varies within $0.12 \pm$ $0.07 \mathrm{mmol} / \mathrm{L}$ ranges, with a $0.09-0.15$ confidence interval. 


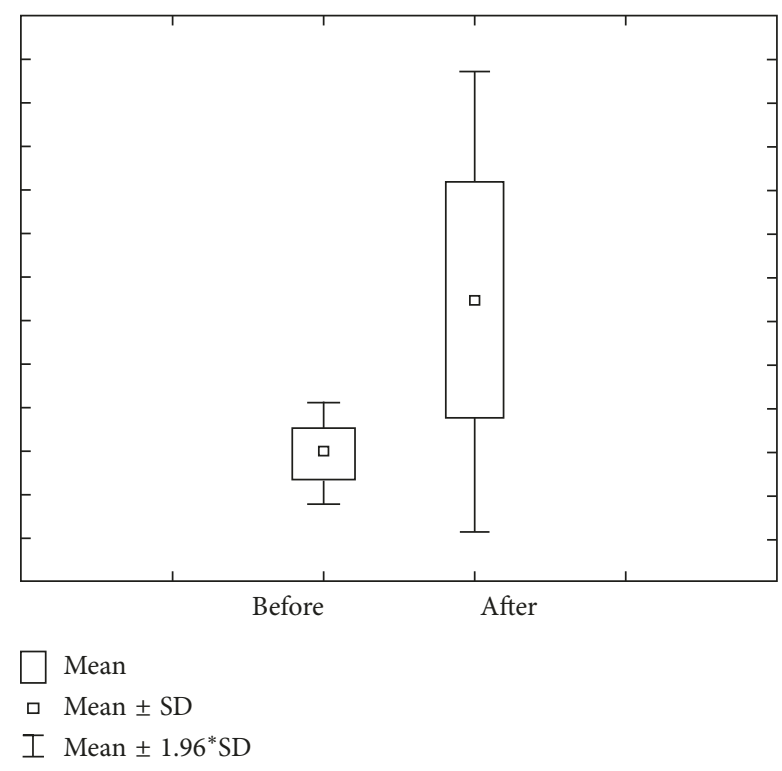

FIGURE 5: Concentration and quantity of Ca before stimulation for the second group of investigated subjects $(\mathrm{DMF}=1-6)$.

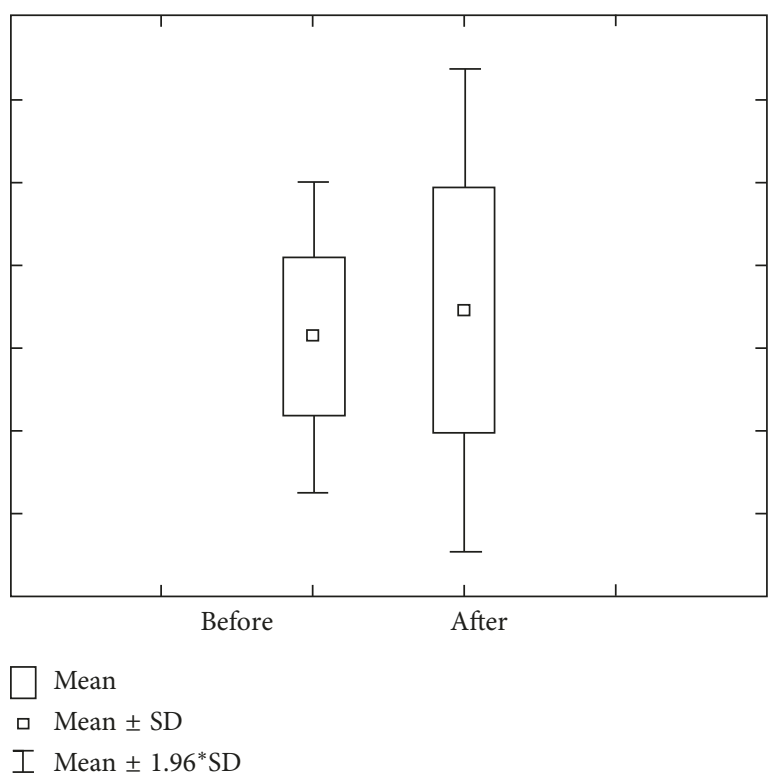

Figure 6: Concentration and quantity of $\mathrm{Ca}$ after stimulation for the second group of investigated subjects $(\mathrm{DMF}=1-6)$.

$\mathrm{Mg}$ concentration after stimulation varies within $0.09 \pm$ $0.03 \mathrm{mmol} / \mathrm{L}$ ranges, with $0.08-0.11$ interval of confidence.

$\mathrm{Mg}$ amount prior stimulation varies within $0.18 \mu \mathrm{mol} / \mathrm{L}$ ranges, with $0.14-0.23$ interval of confidence. $\mathrm{Mg}$ amount after stimulation varies within $0.77 \pm 0.30 \mu \mathrm{mol} / \mathrm{L}$ ranges, with $0.65-0.90$ interval of confidence.

The second group $(\mathrm{DMF}=1-6)$ comprises $47(44.34 \%)$ of total examinees. Figures 5 and 6 show the value of concentration and amount of $\mathrm{Ca}$ before and after stimulation. The concentration of $\mathrm{Ca}$ prior to stimulation varies within $1.07 \pm$ $0.47 \mathrm{mmol} / \mathrm{L}$ ranges, with a $0.93-1.21$ confidence interval. The concentration of $\mathrm{Ca}$ after stimulation varies within $1.23 \pm$

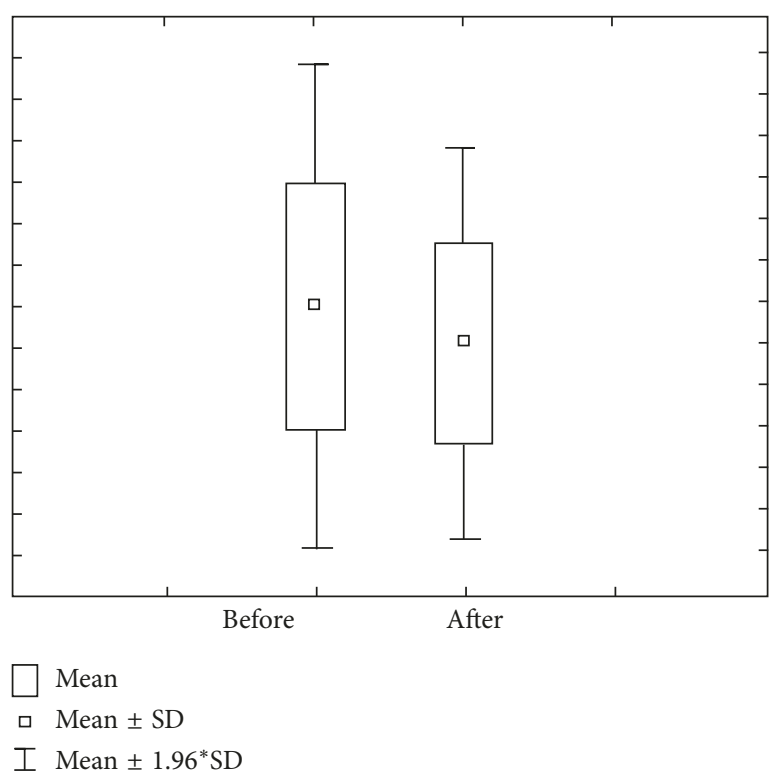

FIgURE 7: Concentration and quantity of $\mathrm{Mg}$ before stimulation for the second group of investigated subjects $(\mathrm{DMF}=1-6)$.

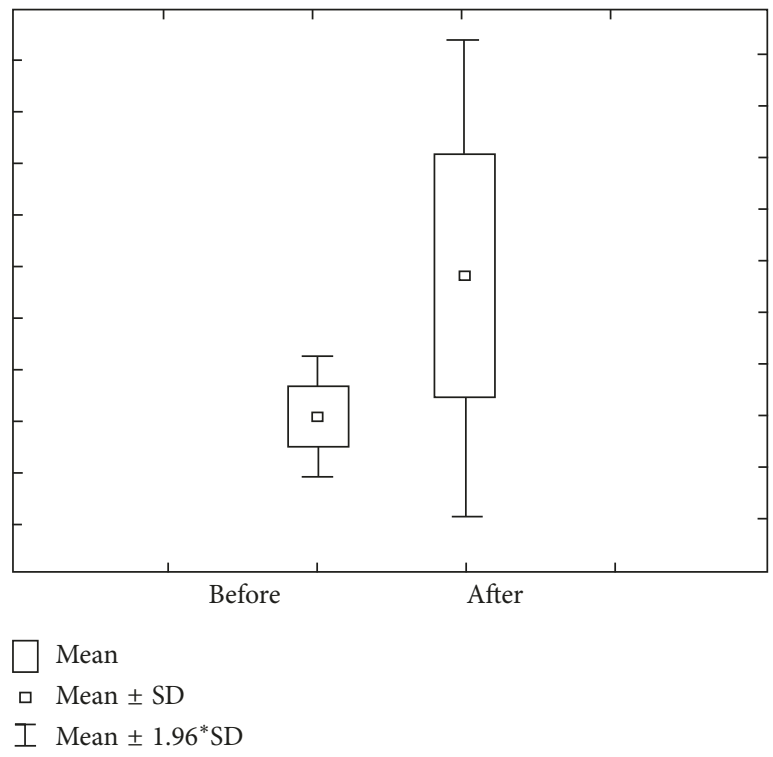

FIGURE 8: Concentration and quantity of $\mathrm{Mg}$ after stimulation for the second group of investigated subjects $(\mathrm{DMF}=1-6)$.

$0.74 \mathrm{mmol} / \mathrm{L}$ ranges, with a 1.01-1.44 interval of confidence. Ca amount prior to stimulation varies within $1.95 \pm 1.18 \mu \mathrm{mol} / \mathrm{L}$ ranges, with a 1.60-2.29 interval of confidence, while Ca amount prior to stimulation varies within $8.95 \pm 5.39 \mu \mathrm{mol} / \mathrm{L}$ ranges, with a 7.37-10.54 interval of confidence.

Figures 7 and 8 show the value of concentration and amount of $\mathrm{Mg}$ before and after stimulation. Concentration of $\mathrm{Mg}$ prior to stimulation varies within $0.11 \pm 0.05 \mathrm{mmol} / \mathrm{L}$ ranges, with $0.10-0.13$ interval of confidence. The concentration of $\mathrm{Mg}$ after stimulation varies within $0.10 \pm$ $0.04 \mathrm{mmol} / \mathrm{L}$ ranges, with $0.08-0.11$ interval of confidence. $\mathrm{Mg}$ amount prior to stimulation varies within $0.21 \pm$ $0.12 \mu \mathrm{mol} / \mathrm{L}$ ranges, with $0.17-0.24$ interval of confidence, 


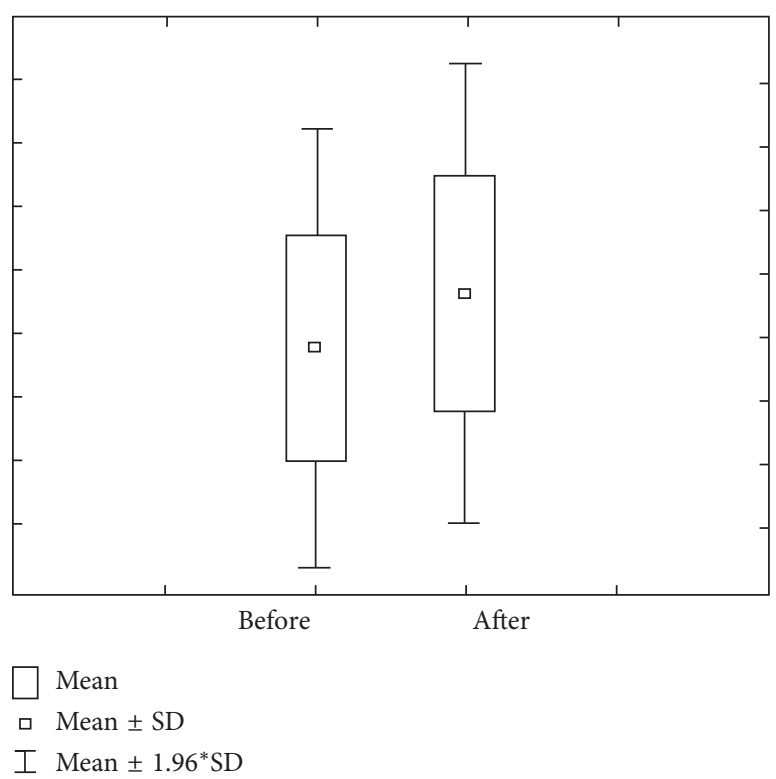

FIgURE 9: Concentration and quantity of $\mathrm{Ca}$ before stimulation for the third group of investigated subjects $(\mathrm{DMF}>6)$.

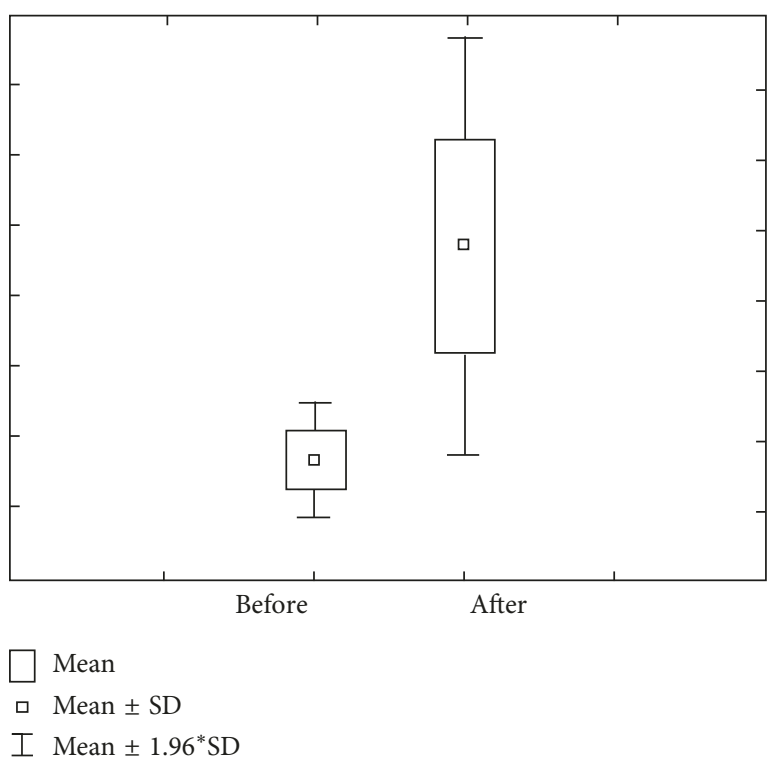

Figure 10: Concentration and quantity of $\mathrm{Ca}$ after stimulation for the third group of investigated subjects $(\mathrm{DMF}>6)$.

while $\mathrm{Mg}$ amount prior stimulation varies within $0.75 \pm$ $0.47 \mu \mathrm{mol} / \mathrm{L}$ ranges, with $0.61-0.88$ interval of confidence.

Figures 9 and 10 show the value of concentration of $\mathrm{Ca}$ before and after stimulation in group $3(\mathrm{DMF}>6)$. Concentration of Ca prior to stimulation varies within $0.95 \pm$ $0.35 \mathrm{mmol} / \mathrm{L}$ ranges, with $0.83-1.08$ interval of confidence. The concentration of $\mathrm{Ca}$ after stimulation varies within $1.13 \pm 0.36 \mathrm{mmol} / \mathrm{L}$ ranges, with $1.00-1.26$ interval of confidence. Ca amount prior to stimulation varies within $1.38 \pm 0.82 \mu \mathrm{mol} / \mathrm{L}$ ranges, with $1.09-1.66$ interval of confidence, while $\mathrm{Ca}$ amount after stimulation varies within $7.50 \pm 3.01 \mu \mathrm{mol} / \mathrm{L}$ ranges, with $6.44-8.55$ interval of confidence.

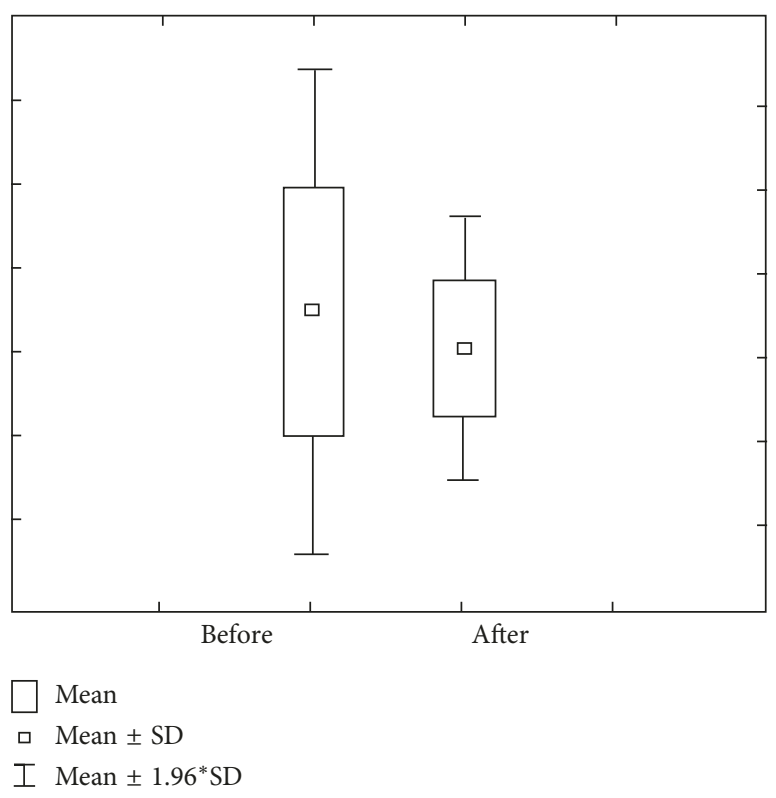

FIGURE 11: Concentration and quantity of $\mathrm{Mg}$ before stimulation for the third group of investigated subjects $(\mathrm{DMF}>6)$.

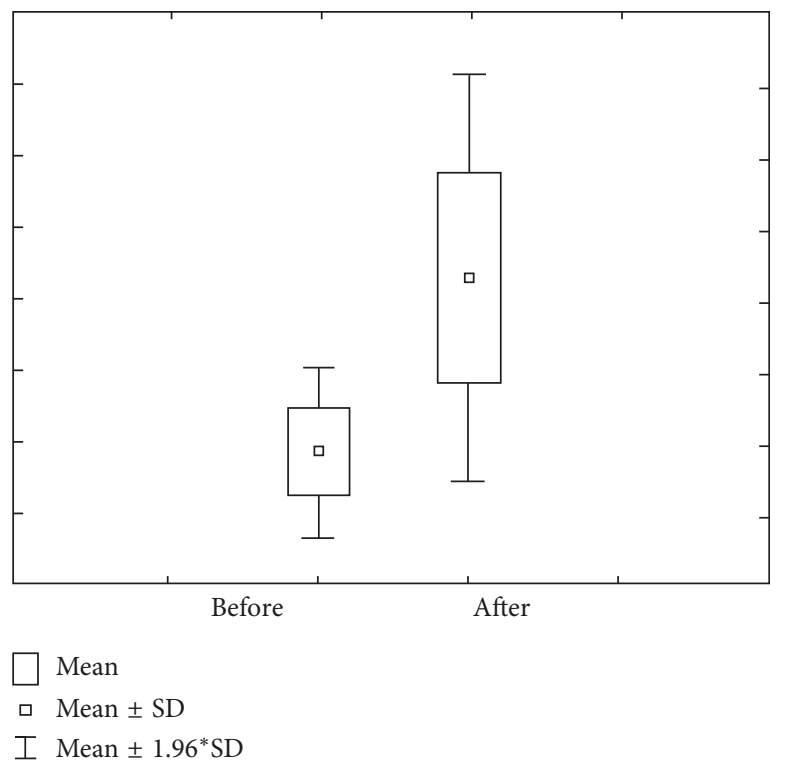

FIgURE 12: Concentration and quantity of $\mathrm{Mg}$ after stimulation for the third group of investigated subjects $(\mathrm{DMF}>6)$.

Figures 11 and 12 show the concentration of Mg before and after stimulation for the third group of the research. Concentration of $\mathrm{Mg}$ prior to stimulation varies within $0.12 \pm 0.07 \mathrm{mmol} / \mathrm{L}$ ranges, with $0.09-0.15$ confidence interval. Concentration of $\mathrm{Mg}$ after stimulation varies within $0.10 \pm 0.04 \mathrm{mmol} / \mathrm{L}$ ranges, with $0.08-0.11$ confidence interval. $\mathrm{Mg}$ amount prior to stimulation varies within $0.17 \pm$ $0.12 \mu \mathrm{mol} / \mathrm{L}$ ranges, with $0.13-0.21$ confidence intervals, while $\mathrm{Mg}$ amount prior to stimulation varies within $0.56 \pm$ $0.76 \mu \mathrm{mol} / \mathrm{L}$ confidence intervals.

The comparison of $\mathrm{Ca}$ concentration before and after stimulation, for $r=0.94(p<0.05)$, indicates the presence of very high correlation (Figure 13), while the comparison of 


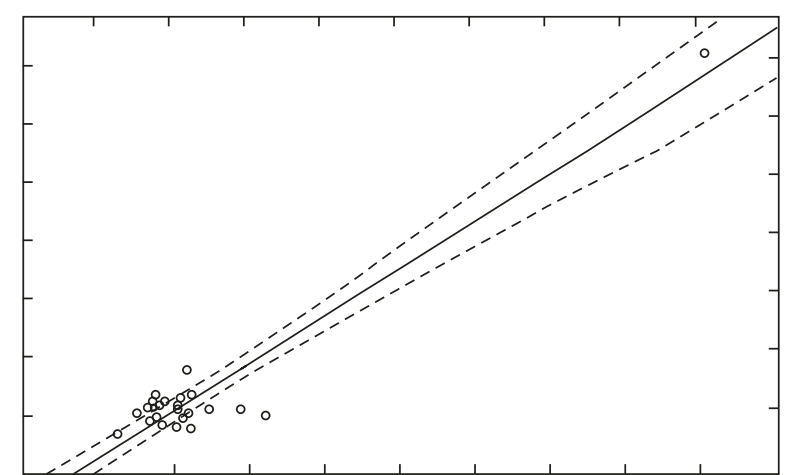

Figure 13: Concentration of Ca before and after stimulation with correlation $r=0.94889$.

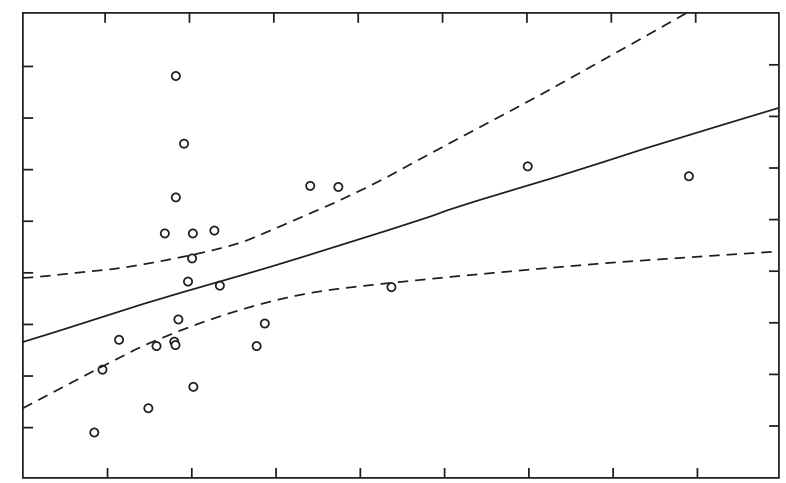

Figure 14: Concentration of $\mathrm{Mg}$ before and after stimulation with correlation $r=0.45492$.

Mg concentration before and after stimulation, for $r=0.45$ $(p<0.05)$, indicates the presence of moderately strong correlation (Figure 14).

A comparison of Ca before and after stimulation for $r=$ $-0.33(p<0.05)$ shows the presence of a weak negative correlation (Figure 15), while the researched report between the concentration of $\mathrm{Ca}$ concentration before stimulation and concentration of $\mathrm{Mg}$ after the stimulation for $r=0.43$ $(p<0.05)$ indicates the presence of moderately high correlation (Figure 16).

\section{Discussion}

There are quantitative differences in the relative proportions of human saliva electrolytes in the major salivary gland secretions. For instance, parotid saliva is relatively low in calcium and high in phosphate as compared to submandibular and sublingual secretions.

Research outcome of native saliva mineral composition has shown major physiological differences in the composition of some minerals in all study groups [8-10] correlating to our results. Caries development, among other things, is in a firm relation to physical and chemical properties of dental enamel, as well as to physical, biochemical, and immunochemical properties of the tooth surroundings. Using electromicroscopic analysis, it is found that established remineralizing solution, consisting of $\mathrm{Ca}, \mathrm{P}$, and $\mathrm{F}$ in an extracted tooth, submerged in artificial saliva and afterward

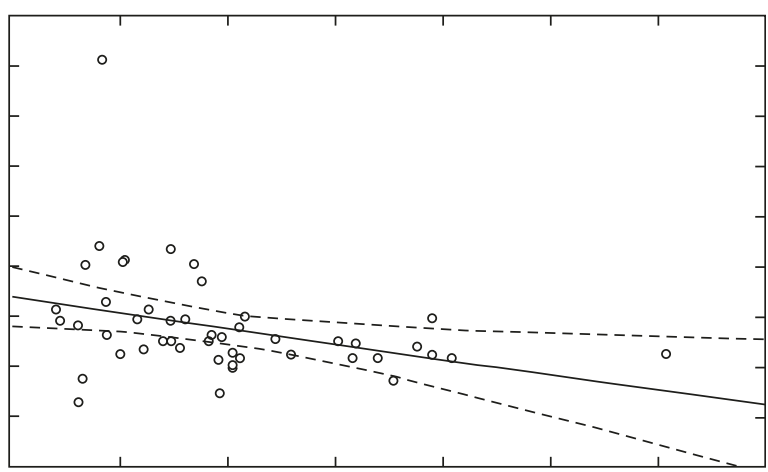

FIGURE 15: Quantity of Ca before and after stimulation, correlation $r=-0.3332$.

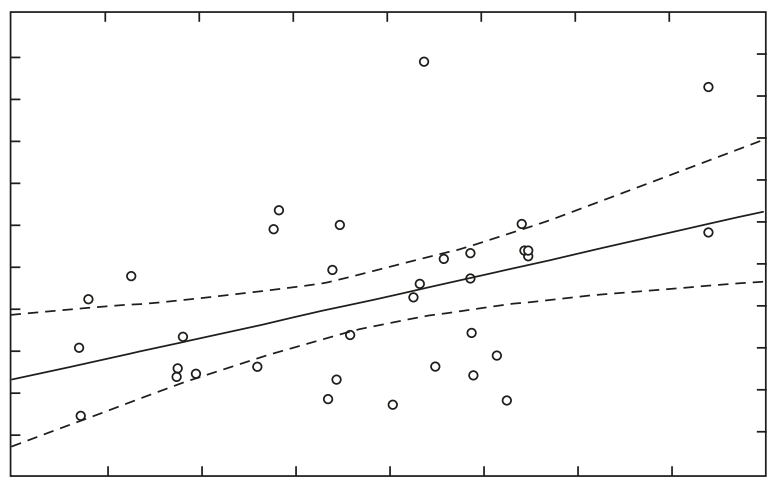

Figure 16: Concentration of $\mathrm{Ca}$ and $\mathrm{Mg}$ before and after stimulation, correlation $r=0.43042$.

in the abovementioned solution, recovers enamel damage (caries, decay) and enhances the remineralizing potential of saliva [11]. It is generally accepted that saliva secretion and its components are of major significance for dental and overall mouth health [12].

Calcium role as fluoride-calcium [13] composition shows a great stability within the oral environment, thanks to the superficial absorbance of $\mathrm{HPO}_{2}$ in a crystal surface, as well as to the establishment of melting phase, limited phase, which can be used as a reservoir with controlled $\mathrm{pH}$ of enamel and dental plaque ions [14].

In a study of the $\mathrm{Ca}$ and $\mathrm{P}$ composition in full and stimulated saliva, it is found that patients with low caries frequency have higher amounts of $\mathrm{Ca}$ ions compared to those with higher caries prevalence, which matches our results too. The saliva of examined students at the age of 12 , affected with severe caries, was characterized with alteration of $\mathrm{Ca}$ homeostasis, companioned with $\mathrm{Ca}$ frequency redistribution within nonstimulated saliva [15]. In this case, mild deviation of the overall $\mathrm{Ca}$ level was noticed. Saliva level of Ca plays a significant role in the dental hard tissue defense system. On the contrary, lower Ca levels in the saliva have enhancing force for hydroxylapatite precipitation in neutral $\mathrm{pH}$ and have the larger force to dissolve hydroxylapatite in even more lower critical pH [16].

Calcium-enriched saliva enables initial damage (caries) remineralization. As mouth rinsing with $\mathrm{Ca}$-enriched saliva fights caries, stimulation of saliva secretion via chewing gum is proved to be efficient too. 
Undersaturation deriving from acidic bacteria production results in caries, while other way round, supersaturation can help in remineralization of white spots [17]. In a study of electrolyte levels, among students with low caries activity and those with caries inclusiveness from 6 to 14, the critical quantitative difference was found [9].

Our study resulting from statistical tests show that, in the saliva of students with caries, there is a significant correlation between $\mathrm{Ca}$ and $\mathrm{Mg}$ levels. It is thought that this was important for proper mineralization, but also, it is foreseen that for maturation purposes, higher levels are needed [18]. Studies carried out on mineral composition of nonstimulated native saliva are few, moreover, with contradictory results. These oscillations of electrolyte physiological volume sphere are induced by optimal secretion velocity and by glandular secretion composition alteration, with the following key players: gender, day period, diet, emotional, and health condition.

A higher value of the deft index was associated with lower amounts of daily $\mathrm{Ca}$ or $\mathrm{P}$ intake. Because the associations were no longer significant after adjusting for potential confounding factors, one could speculate that the daily dietary intakes of $\mathrm{Ca}$ or $\mathrm{P}$ might not be the primary nutritional factors for caries [19].

The decrease in Ca levels results in a reduction of enamel crystallinity, increasing one's retentive surface and decreasing overall resistance. In a study of saliva Ca levels, carried out on 23 caries-affected students and 32 unaffected ones, it is found that Ca levels in noncariotic students are far higher, compared to cariotic ones [10]. In a caries intensityrelated study of qualitative composition and secretion of mixed saliva in a group of 264 students (6-14 y.o.), the correlation was found between saliva $\mathrm{Ca}$ composition, qualitative secretion, and teeth resistance against caries. Calcium levels in serum and saliva are decreased in cariesprone individuals. Our findings are a complete match to this study.

Regarding studies carried out on Ca molality of mixed saliva in caries-affected and not affected students, the data obtained from our study are matching Liappis and Konstantine findings [9] and not matching Tokyeva [20] and Show et al. [10] findings. A study conducted on 70 healthy patients, in collected saliva samples, $\mathrm{Mg}$ composition was analyzed in three different study groups: 7-14 y.o., 18-28 y. o., and 48-60 y.o. Significant age-related Mg level difference is found between groups I and II, as well as between groups I and III [21]. The composition and the level of inorganic ions in dental plaque and saliva are significantly influencing the initiation and development of caries via saturation level alteration in the watery phase surrounding dental enamel. The level of inorganic ions of $\mathrm{Ca}$ and $\mathrm{Mg}$ differs significantly between plaque liquid and saliva [22]. This means saliva and plaque liquid differ in inorganic composition, probably due to plaque bacteria metabolic activity. Regarding correlation coefficient between dental plaque and saliva composition, a significant correlation between $\mathrm{Mg}$ ions and not $\mathrm{Ca}$ ions are found. As previous studies claim, Mg continuously incorporates in dental tissues, while simultaneously, the same amount is lost through attrition, and thus, no deficiency occurs. Since Mg through ionic exchange can substitute Ca, loss of crystal density may occur, explaining the increase of caries predisposition in an environment with a higher level of $\mathrm{Mg}$ than $\mathrm{Ca}$.

Reduction of crystal density inside enamel is in direct correlation to higher level $\mathrm{Mg}$ and $\mathrm{CO}_{2}$ ions [23]. In a prospective study of saliva $\mathrm{Mg}$, with the spectrophotometric atomic absorption of 186 patients treated with digoxin, it is found that salivary $\mathrm{Mg}$ level is correlated with the digoxin level in plasma; an obvious increase of salivary $\mathrm{Mg}$ level was induced due to digoxin therapy [21]. The amount of salivary $\mathrm{Ca}$ and $\mathrm{Mg}$ is correlated to alteration of the same mineral levels in blood serum; thus, $\mathrm{Ca}$ infusion administration did not change the overall $\mathrm{Ca}$ and other mineral levels in saliva [14].

\section{Conclusion}

In this study, we can conclude that

(i) the $\mathrm{Ca}$ concentration before and after saliva stimulation and the quantity of Ca before and after saliva stimulation have shown a high correlation. Calcium level significantly influences hard dental tissues defense mechanism;

(ii) calcium level after stimulation with $Z=0.76$, $p>0.05$, is altered significantly compared to the same ones prior to stimulation. With the increase of caries number, the calcium level decreases;

(iii) the level and the composition of $\mathrm{Mg}$ have been monitored; it is calcium-related and goes in favor of elemental caries resistance;

(iv) the relationship between the concentration of $\mathrm{Mg}$ before and after saliva stimulation and the relationship of $\mathrm{Mg}$ quantity before and after saliva stimulation have shown a medium-high correlation;

(v) the Mg level, even after stimulation, did not show significant alterations. The level of $\mathrm{Mg}$ for $t=9.90$ and $p<0.001$ was significantly higher after stimulation, while $\mathrm{Mg}$ level between groups after stimulation was increased, and a significant difference was found between groups I and III and not between groups I and II;

(vi) the amount of $\mathrm{Ca}$ before and after saliva stimulation and the amount of $\mathrm{Mg}$ before and after saliva stimulation have shown a low negative correlation;

(vii) the level of $\mathrm{Ca}$ and $\mathrm{Mg}$ in caries sensitive children could have been appropriate in order to maintain the balance between demineralization and remineralization of the enamel;

(viii) sensitivity of the tooth to caries may be due to differences in chemical composition of the enamel structure.

\section{Conflicts of Interest}

The authors declare that they have no conflicts of interest. 


\section{References}

[1] U. Ackermann, PDQ Physiology: Chapter 8. Gastrointestinal System, B.C. Decker Inc., Ontario, Canada, 2002.

[2] A. Yoshihara, R. Watanabe, N. Hanada, and H. Miyazaki, “A longitudinal study of the relationship between diet intake and dental caries and periodontal disease in elderly Japanese subjects," Gerodontology, vol. 26, no. 2, pp. 130-136, 2009.

[3] R. F. Wilson and F. P. Ashley, "The relationship between the biochemical composition of dental plaque from both approximal and free smooth surfaces of teeth and subsequent 3 -year caries increment in adolescents," Archives of Oral Biology, vol. 35, no. 12, pp. 933-937, 1990.

[4] L. A. Sewón, S. M. Karjalainen, M. Sainio, and O. Seppä, "Calcium and other salivary factors in periodontitis-affected subjects prior to treatment," Journal of Clinical Periodontology, vol. 22, no. 4, pp. 267-270, 1995.

[5] W. A. Aun, "Inorganic ions level in saliva of patients with chronic periodontitis and healthy subjects," Journal of Baghdad College of Dentistry, vol. 24, p. 93, 2012.

[6] J. M. MacKeown, P. E. Cleaton-Jones, and P. Fatti, "Caries and micronutrient intake among urban South African children: a cohort study," Community Dentistry and Oral Epidemiology, vol. 31, no. 3, pp. 213-220, 2003.

[7] M. Jawed, S. M. Shahid, S. A. Qader, and A. Azhar, "Dental caries in diabetes mellitus: role of salivary flow rate and minerals," Journal of Diabetes and its Complications, vol. 25, no. 3, pp. 183-186, 2010.

[8] P. J. Agget, "Physiology and metabolism of essential trace elements: an outline," Clinics in Endocrinology and Metabolism, vol. 14, no. 3, pp. 513-543, 1985.

[9] N. Liappis and T. Konstatinou, "Verhalten der konzentration von Natrium, Kalium, Chloris, anorganischen Phospat, Calcium, Glucose, Harnaöre, Harnstoff-N und kreatinin in speichelgesunder Kindernmitmiedriger und boherkariessaktivitat," Zahn-, Mund-, Und Kieferheilkunde Mit Zentralblatt, vol. 72, pp. 657-662, 1984.

[10] L. Shaw, I. J. Muray, C. K. Ruchell, and Y. S. Best, "Calcium and Phosphorus of plaque and saliva in relation to dental caries," Caries Research, vol. 17, no. 6, pp. 543-548, 1983.

[11] S. Karmad and S. G. Damle, "Effects of a specially formulated remineralizing solution on the remineralizing capacity of saliva," Journal of Indian Society of Pedodontics and Preventive Dentistry, vol. 14, no. 1, pp. 1-5, 1996.

[12] J. D. Mandel, "The role of saliva in maintaining oral homeostasis," Journal of the American Dental Association, vol. 119, no. 2, pp. 298-304, 1989.

[13] G. Rolla, "On the role of calcium fluoride in the cariostatic mechanism Of fluoride," Acta Odontologica Scandinavica, vol. 46, no. 6, pp. 341-345, 1988.

[14] G.-B. Sagulin, O. Tørring, H. E. Sjöberg, S. Arver, and B. Appelgren, "Effects of a three-hour calcium clamp on calcium, phosphate, magnesium and zinc concentrations of human parotid saliva," Acta Physiologica Scandinavica, vol. 124, no. 1, pp. 1-4, 1985.

[15] V. M. Elizarova and I. A. Petrovich, "Calcium homeostasis disorders in children with multiple caries," Stomatologija (Mosk), vol. 81, no. 1, pp. 67-71, 2002.

[16] P. Anderson, M. P. Hector, and M. A. Rampersad, "Critical $\mathrm{pH}$ in resting and stimulated whole saliva in groups of children and adults," International Journal of Paediatric Dentistry, vol. 11, no. 4, pp. 266-273, 2001.

[17] J. M. Ten Cate, "Saliva a physiological medium," Nederlands Tijdschrift Voor Tandheelkunde, vol. 99, no. 3, pp. 82-84, 1992.
[18] G. N. Jenkins, "Current concepts concerning the development of dental caries," International Dental Journal, vol. 22, pp. 350-361, 1972.

[19] H. S. Lin, J. R. Lin, S. W. Hu, H. C. Kuo, and Y. H. Yang, "Association of dietary calcium, phosphorus, and magnesium intake with caries status among schoolchildren," Kaohsiung Journal of Medical Sciences, vol. 30, no. 4, pp. 206-212, 2014.

[20] L. Tokyeva, "Mixed saliva calcium and inorganic phosphorus, the rate of saliva excretion and the caries resistance of the teeth during of the mineralization period in children," Stomatologia (Mosk), vol. 62, no. 4, p. 342, 1983.

[21] M. Cieslak, T. Jedrzejewska, and A. Zgirski, "Determinations of Magnesium, iron and copper in the saliva of healthy subjects," Czasopismo Stomatologiczne, vol. 43, no. 4, p. 202, 1990.

[22] J. Buczowska-Radlinska, "Factors that modify de -and remineralization in dental Enamel from the aspect of caries susceptibility," Annales Academiae Medicae Stetinensis, vol. 47, no. 1, pp. 1-89, 1999.

[23] H. M. Theuns, J. W. E. Vand Dijk, W. E. JongenLoed, and A. Groenceld, "The mineral content of human enamel studied by polarizing microscopy, microradiography and scanning electron microscopy," Archives of Oral Biology, vol. 9, no. 9, pp. 797-801, 1983. 


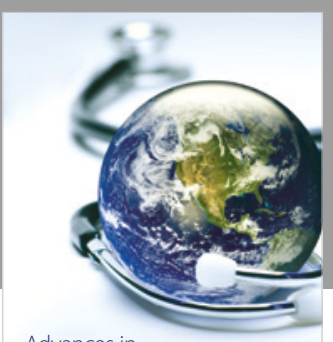

Advances in
Public Health

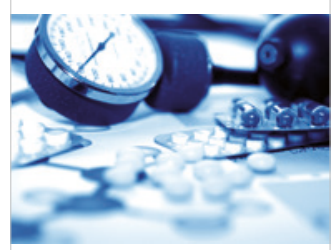

Case Reports in

Medicine

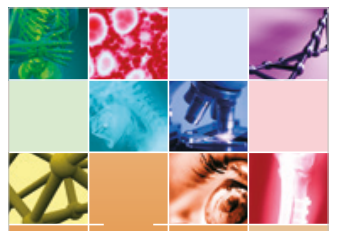

niernational Journal of

Biomaterials
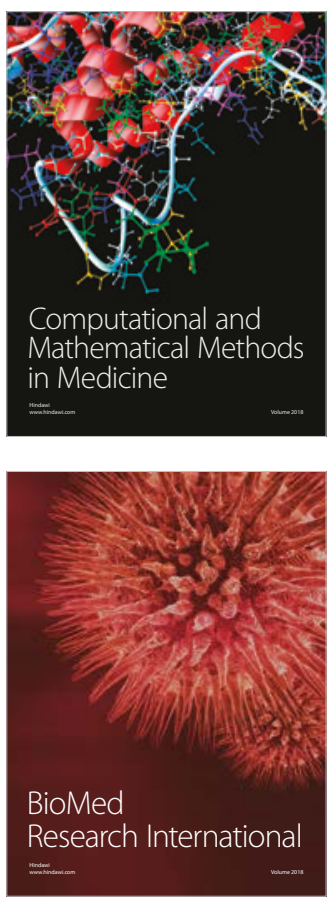

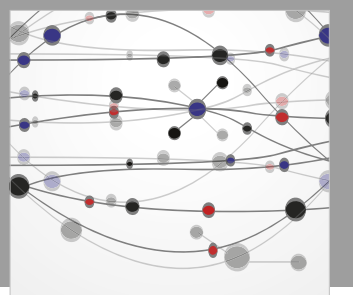

The Scientific World Journal Dentistry

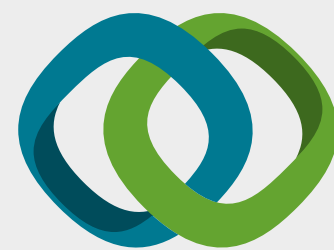

Hindawi

Submit your manuscripts at

www.hindawi.com
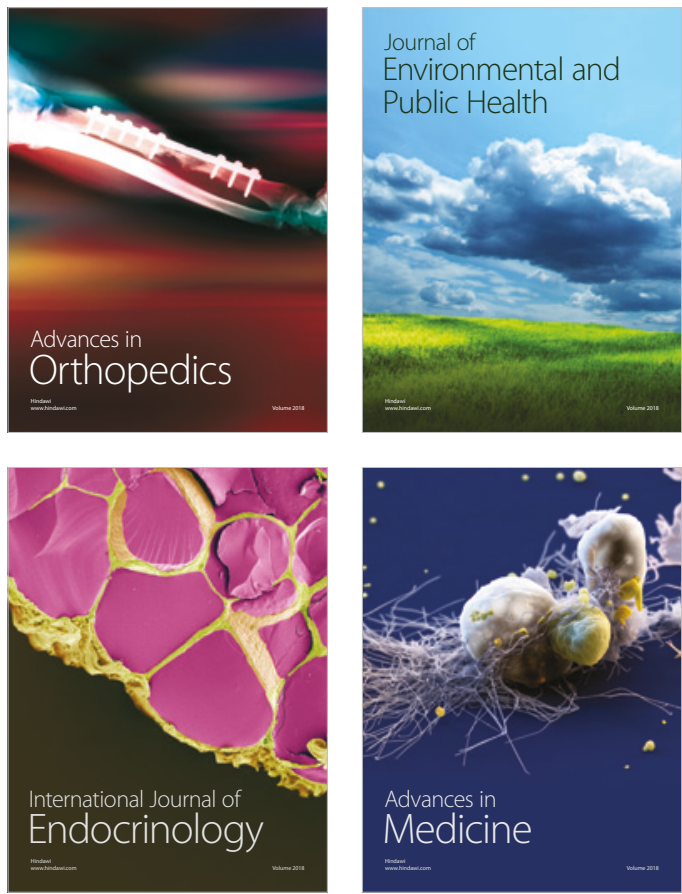
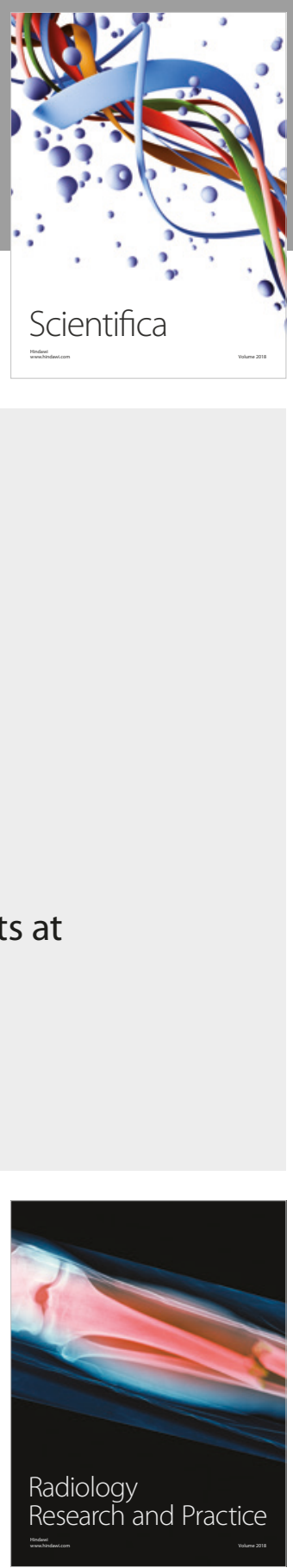

Scientifica

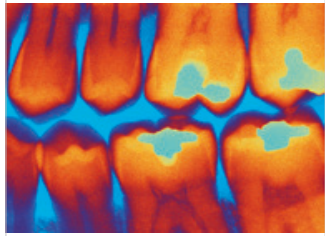

Case Reports in

Dentistry
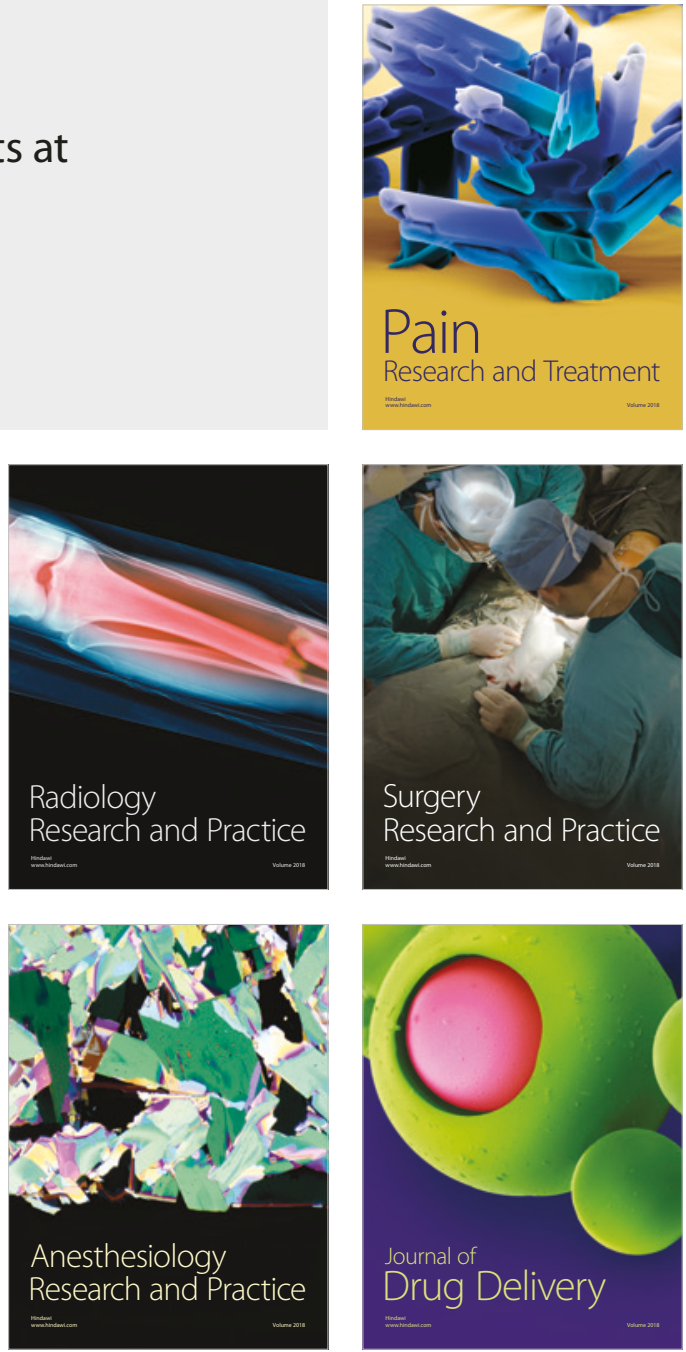